\title{
REPERTORIO BIBLIOGRÁFICO SOBRE LA REFORMA CONSTITUCIONAL
}




\title{
REPERTORIO BIBLIOGRÁFICO SOBRE LA REFORMA CONSTITUCIONAL
}

\author{
LUIS I. GORDILLO PÉREZ \\ Profesor de Derecho Constitucional \\ Universidad de Deusto
}
SUMARIO.
Nota preliminar.
I. Obras generales
II. Estudios sobre la reforma de órganos consti- tucionales.
III. Comunidades Autónomas y reforma constitu- cional.
IV. Integración europea y reforma constitucional.
V. La reforma del artículo $135 \mathrm{CE}$.

\section{NOTA PRELIMINAR}

Suele decirse que la reforma de la Constitución es un mecanismo que permite la adaptación de la misma a las nuevas realidades y necesidades de la sociedad, garantizando así la continuidad jurídica del Estado (De Vega).

En España, sin embargo, y ya desde las primeras andaduras de nuestra Constitución, parece que se ha ido optando por arreglos, parches y remiendos varios al margen de la Constitución formal. La importación, con la consiguiente adaptación, de categorías como el bloque de la constitucionalidad permitieron en su momento solucionar problemas de interpretación y facilitar la integración del ordenamiento, ante la complejidad de la llamada «Constitución territorial» española. Todo ello, sin mencionar, las interpretaciones que parecen alejarse de la literalidad de la norma (o, directamente, contrarias a la Constitución), el uso y el abuso de los mecanismos del artículo 150.2 y otros usos y costumbres sobre los que no conviene extenderse ahora.

El caso es que en nuestro país, hasta el momento, las dos únicas reformas de la Constitución que han salido adelante comparten ciertos elementos en común. Por un lado, ambas se llevaron a cabo casi de un día para otro (en la del 13.2, hay que reconocer que hubo un apresurado debate sobre la conveniencia o no de la reforma) y ambas parecieron 
venir «impuestas» por las necesidades de la integración europea (con un marcado perfil económico, en el caso del 135). No es que en España no exista debate sobre la necesidad de reformar algunos pasajes de la Constitución, incluso habría cierto consenso en determinados aspectos, pero parece que nadie se atreve a «abrir el melón de la reforma constitucional» por aquello de que los unos y los otros recuerden aquello de «¿qué hay de lo mío?».

La doctrina española que se ha dedicado al tema de reforma, ha realizado, al igual que sus homólogos europeos, estudios críticos del mecanismo de reforma, se ha cuestionado con brillantez su naturaleza jurídica, empleando gran parte de sus esfuerzos en el análisis de los límites al poder de reforma. Además, de ellos, y por razones que tienen que ver con la problemática del complejo Estado de las Autonomías, existen desde siempre numerosos estudios sobre el Senado que conviven con líneas doctrinales más recientes relativas a la necesidad de replantear el encaje constitucional de España en la UE (léase, reforma del artículo 93). Todo ello sin olvidar estudios que han preconizado la necesidad de acabar con la preterición de la mujer en la sucesión a la Corona.

Esta recopilación intenta aportar una muestra lo más completa posible sobre los estudios de la doctrina española (con la inclusión de algún trabajo foráneo que fue traducido al castellano, como los de Bryce y Jellinek con sendos estudios preliminares de P. Lucas Verdú). La estructura que se ha elegido, y que consta en el sumario, incluye, una recopilación de obras sobre la teoría general de la reforma (donde abundan los trabajos sobre los límites a dicho poder), una sección dedicada al Senado, otra a la Corona, otra al resto de órganos constitucionales, una a las Comunidades Autónomas, otra a Europa y una última que recoge los pocos trabajos de los que se ha tenido noticia que estudian la última y apresurada reforma del artículo 135. Todo ello, sin olvidar un apartado (1.3) dedicado a estudios particulares sobre algunos aspectos específicos o más marginales (en el sentido de poco analizados por la doctrina).

A la hora de elaborar este repertorio, se ha tenido que ser muy selectivo en el caso de la reforma del Senado, so pena de transformar esta recopilación en un monográfico sobre la Cámara Alta. Además, se ha prescindido de importantes obras en Derecho comparado y de algunos artículos en inglés, francés, alemán o italiano de la doctrina española. La razón obedece a una interpretación estricta del autor sobre la finalidad de este trabajo: realizar una recopilación de la doctrina española sobre la reforma constitucional en idioma castellano. También se han tenido que dejar de lado los capítulos de los manuales clásicos que tratan este tema. No obstante, siendo uno de los temas básicos de la disciplina, quien desee entender correctamente el concepto, naturaleza, mecanismos e implicaciones de la reforma constitucional ha de comenzar indefectiblemente con la lectura de los manuales de Álvarez Conde, Alzaga Villaamil, Balaguer Callejón (et al.), Garrorena, González Casanova, López Guerra/Pérez Tremps (et. al.), Pérez Royo, Otto, Pérez Serrano, Torres del Moral y otros normalmente utilizados en la docencia universitaria.

A buen seguro el autor se habrá dejado algún trabajo importante. No ha sido su intención. Las ausencias se deberán más bien a su desconocimiento o ignorancia. En todo caso, si no están todos los que son, sí que son todos los que están. 


\section{OBRAS GENERALES}

\section{II.1. RECOPILACIONES Y MONOGRÁFICOS}

ÁlVAREZ JUNCO, J., RUBIO LLORENTE, F. (eds.), El informe del Consejo de Estado sobre la reforma constitucional: texto del informe y debates académicos, CEPC y Consejo de Estado, Madrid, 2006.

Boletín de Documentación del Centro de Estudios Políticos y Constitucionales, núms. 19-20, (Contiene Dossier sobre «La reforma constitucional en España 2004.

Boletín de Documentación del Centro de Estudios Políticos y Constitucionales, núms. 17-18 (Contiene Dossier sobre «La reforma constitucional en los países de la Unión Europea «), 2003.

Parlamento y Constitución (Anuario), núm. 8 (Ejemplar dedicado a: Reforma de la Constitución), 2004.

Revista de Derecho Político, núms. 36 y 37 (especial sobre La reforma constitucional), 1992. Recogen las aportaciones al Congreso «La Reforma de la Constitución», cuyas actas también fueron publicadas como VV. AA., Congreso «La Reforma de la Constitución»: La Rioja, 27, 28, 29 y 30 de abril de 1992, Gobierno de la Rioja, Logroño, 1992.

Revista española de la función consultiva, núm. 4, (Ejemplar dedicado a: Reforma de los Estatutos de Autonomía y Reforma de la Constitución), 2005.

ROURA GÓMEZ, S. A., TAJADURA TEJADA, J. (coords.), La reforma constitucional: la organización territorial del Estado, la Unión Europea y la igualdad de género, Biblioteca Nueva, Madrid, 2005.

VV. AA., La reforma constitucional, Ministerio de Justicia, Madrid, 2005.

\section{I.2. TEORÍA GENERAL: LA REFORMA CONSTITUCIONAL Y SUS LIMITACIONES}

ACOSTA SÁNCHEZ, J., «Poder constituyente y problemática de la reforma en la Constitución española», GONZÁLEZ RUS, J. J., Estudios penales y jurídicos: homenaje al Prof. Dr. Enrique Casas Barquero, Servicio de Publicaciones de la Universidad de Córdoba, 1996, pp. 19-32.

AGUILERA DE PRAT, C., «El uso del referéndum en la España democrática (1976-1986)», Revista de Estudios Políticos, núm. 75, 1992, pp. 131-163.

ALÁEZ CORRAL, B., «La CE de 1978: ¿Ruptura o reforma constitucional?», Anuario de Derecho Constitucional y Parlamentario, núm. 9, 1997, pp. 161-190.

ALÁEZ CORRAL, B., «La reforma constitucional como motor de las transformaciones actuales del Estado español», CARRASCO DURÁN, M., PÉREZ ROYO, J., URÍAS MARTÍNEZ, J. y TEROL BECERRA, M. J., Derecho constitucional para el siglo XXI: actas del VIII Congreso Iberoamericano de Derecho Constitucional, Thompson-Aranzadi, Madrid, Vol. 1, 2006, pp. 465-488. 
ALÁEZ CORRAL, B., «Supremacía y rigidez constitucionales», Revista española de derecho constitucional, núm. 47, 1996, pp. 373-391.

ALÁEZ CORRAL, B., Los límites materiales a la reforma de la Constitución Española de 1978, BOE-CEPC, Madrid, 2000.

ÁLVAREZ CONDE, E., «Reforma constitucional y reformas estatutarias», Revista española de la función consultiva, núm. 4, (Ejemplar dedicado a: Reforma de los Estatutos de Autonomía y Reforma de la Constitución), 2005, pp. 35-78.

ÁLVAREZ CONDE, E., «Reforma constitucional y reformas estatutarias», Cuadernos de pensamiento político FAES, núm. 11, 2006, pp. 43-100. 2007.

ÁLVAREZ CONDE, E., Reforma constitucional y reformas estatutarias, Iustel, Madrid,

ÁLVAREZ CONDE, E., «Reflexiones sobre la reforma constitucional y los actuales procesos de reformas estatutarias», GARRIDO MAYOL, V., CATALÀ I BAS, A. H., GARCÍA MENGUA, F., Modelo de Estado y reforma de los estatutos, Fundación Profesor Manuel Broseta, Valencia, 2007, pp. 41-64.

ALZAGA VILLAAMIL, Oscar: «Entre el santo temor a la reforma de la Constitución de 1978 y la conveniencia de pensar en ella», LAMO DE ESPINOSA, E., PARDO, R., TUSELL, J., (eds.), Entre dos Siglos: reflexiones sobre la democracia española, Alianza Editorial, Madrid, 1996, pp. 79-109.

APARICIO PÉREZ, M., «¿Qué reforma constitucional?», Revista d'estudis autonòmics i federals, núm. 2, 2006, pp. 101-124.

ARGÜELLES, A., Examen bistórico de la reforma constitucional de España, Junta General del Principado de Asturias, Oviedo, 1999.

BALAGUER CALLEJÓN, F., «Fuentes del Derecho y reforma de la Constitución», Revista de Derecho Político, núm. 36 (especial sobre La reforma constitucional), 1992, pp. 407-418.

BALAGUER CALLEJÓN, F., «El «status» constitucional de la reforma y la «fragmentación» del poder constituyente», VV. AA., La democracia constitucional. Estudios Homenaje a Francisco Rubio Llorente, CEPC, Madrid, 2002, Vol. I, pp. 99-130.

BARRERO ORTEGA, A., «La transformación de la Constitución española a la luz del Derecho constitucional europeo», Revista de derecho constitucional europeo, núm. 10, 2008, pp. 365-386.

BELDA PÉREZ-PEDRERO, E., «Materiales doctrinales para la reforma constitucional en España», Parlamento y Constitución, núm. 8, 2004, pp. 185-200.

BELDA PÉREZ-PEDRERO, E., «Reforma constitucional: definición de qué, cómo y cuándo, y protagonismo del modelo territorial», VV. AA., La reforma constitucional, Ministerio de Justicia, Madrid, 2005, pp. 55-68.

BLANCO VALDÉS, R., «Reforma constitucional y política de la Constitución», JIMÉNEZ DE PARGA, M., VALLESPÍN OÑA, F., La Política, Biblioteca Nueva, Madrid, 2008, pp. 309-342. 
BLANQUE AVILÉS, L., BLANQUE REY, L., «Breves consideraciones sobre la reforma constitucional», VV. AA., La reforma constitucional, Ministerio de Justicia, Madrid, 2005, pp. 139-152.

BOZA MARTÍNEZ, D., «Las cláusulas de irreformabilidad en las Constituciones de los Estado de la Europa de los 25», Parlamento y Constitución, núm. 8, 2004, pp. 201216.

BRYCE, J., Constituciones flexibles y Constituciones rígidas, Instituto de Estudios Políticos, Madrid, 1952 (Estudio Preliminar de P. Lucas Verdú).

BULIGYN, E., «La Paradoja de la Reforma Constitucional», VV. AA., Alf Ross: estudios en su homenaje, Edeval, Valparaíso, 1984, Vol. 1, pp. 329-336.

CALZADA CONDE, R, La reforma constitucional y las mutaciones en el ordenamiento constitucional, Universidad de Salamanca, Salamanca, 1987.

CALZADA CONDE, R., «La garantía normativa de la rigidez», VV. AA., Introducción a los Derechos Fundamentales. X Jornadas de estudio, Ministerio de Justicia, Madrid, 1988, pp. 385-406.

CALZADA CONDE, R., «Reflexiones en torno a la reforma constitucional», Cuadernos constitucionales de la Cátedra Fadrique Furió Ceriol, núm. 5, 1993, pp. $49-67$.

CAVERO LATAILLADE, I., «Lo reformable en la Constitución de 1978», VV. AA., Estructura y cambio social: homenaje a Salustiano del Camp, Centro de Investigaciones Sociológicas, Madrid, 2001, pp. 481-490.

COHEN, M. J., Jaque a la Constitución: déficits democráticos del actual sistema constitucional español y consideraciones sobre su reforma, Alfosípolis, Cuenca, 2004.

CONTRERAS CASADO, M., «La reforma constitucional», RAMÍREZ, M., Estudios sobre la Constitución Española de 1978, Libros Pórtico, Zaragoza, 1979, pp. 3403-3421.

CONTRERAS CASADO, M., «Sobre el Título X de la Constitución Española: de la reforma constitucional», Revista de Derecho Político, núm. 37 (especial sobre La reforma constitucional), 1992, pp. 303-318.

CONTRERAS CASADO, M., «Sobre el Título X de la Constitución Española: de la reforma constitucional», Revista de Derecho Político, núm. 37 (especial sobre La reforma constitucional), 1992, pp. 303-318.

CONTRERAS CASADO, M., «Un nuevo enfoque de la reforma constitucional y sus límites materiales», Revista española de derecho constitucional, núm. 65, 2002, pp. 381-386.

CRUZ VILLALÓN, P., «Constitución y reforma», Claves de Razón Práctica, núm. 115, 2001, pp. 4-7.

DAGNINO GUERRA, A., Una propuesta de reforma constitucional, CEU Ediciones, Madrid, 2007.

DE CABO MARTÍN, C., La reforma constitucional en la perspectiva de las fuentes del derecho, Trotta, Madrid, 2003.

DE CABO MARTÍN, C., «Constitución y reforma», GARCÍA HERRERA, M. A., Constitución y democracia: 25 años de Constitución democrática en España (actas del congreso ce- 
lebrado en Bilbao los días 19 a 21 de noviembre de 2003), UPV-CEPC, Bilbao, 2003, pp. 635-651.

DE VEGA, P., La reforma constitucional y la problemática del poder constituyente, Tecnos, Madrid, 1985.

DÍAZ REVORIO, F. J., Valores superiores e interpretación constitucional CEPC, Madrid, 1997.

DÍAZ REVORIO, F. J., «Perspectivas de reforma de la Constitución española», Parlamento y Constitución, núm. 8, 2004, pp. 11-38.

DÍAZ RICCI, S. M., Teoría de la reforma constitucional, UNAM-UCM-Ediar, Buenos Aires, 2004.

DIEZ-PICAZO GIMÉNEZ, L. M., «Límites internacionales al poder constituyente», Revista Española de Derecho Constitucional, núm. 76, 2006, pp. 9-32.

D'OLIVEIRA MARTINS A., «La revisión constitucional y sus límites materiales no expresados», MORODO LEONCIO, R., DE VEGA, P. (coord.), Estudios de teoría del Estado y derecho constitucional en honor de Pablo Lucas Verdú, Universidad Complutense de Madrid, 2001, Vol. 2, pp. 1199-1224

EMBID IRUJO, A., «¿Reforma de la Constitución y de Estatutos de Autonomía?: Aportaciones a un debate de actualidad», Justicia Administrativa: Revista de Derecho Administrativo, núm. 22, 2004, pp. 5-17.

FARIAS GARCIA, P., «Consideraciones sobre la reforma constitucional», Revista General de Legislacion y Jurisprudencia, núm. 3, 1979, pp. 251-265.

FERRERES COMELLA, V., «Una defensa de la rigidez constitucional», Doxa: Cuadernos de Filosofía del Derecho, núm. 23, 2000, pp. 29-47.

FRAGA IRIBARNE, M., «Reforma política y reforma constitucional», VV. AA., Fenómenos de crisis y futuro de España, Unión Editorial, Madrid, 1981, pp. 115-134.

FRAGA IRIBARNE, M., Ideas para el desarrollo constitucional, INAP, Madrid, 2003.

GARCÍA GESTOSO, N., «La reforma de la Constitución en el estado constitucional: su significado, funciones y alcance», Anuario de la Facultad de Derecho de Ourense, núm. 1, 2008, pp. 145-174.

GARCÍA LÓPEZ, E., «Democracia cívica y reforma constitucional: el proceso de revisión constitucional en España», Anuario de la Facultad de Derecho de Ourense, núm. 1, 2002, pp. 195-209.

GARCÍA-ATANCE GARCÍA DE MORA, M. V., «La reforma constitucional» FERNÁNDEZ, T. R., Lecturas sobre la CE, UNED, Madrid, 1978, Vol. II, pp. 305-322.

GARCÍA-ATANCE GARCÍA DE MORA. M., «Perfil ambivalente de la fórmula de reforma constitucional en la dialéctica permanencia-cambio», Revista de Derecho Político, núm. 31, 1990, pp. 143-196.

GARCÍA-ATANCE GARCÍA DE MORA, M. V., «La reforma constitucional y las cláusulas de intangibilidad», Revista de Derecho Político, núm. 37 (especial sobre La reforma constitucional), 1992, pp. 319-330. 
GARCÍA-ATANCE GARCÍA DE MORA, M. V., Reforma y permanencia constitucional, CEPC, Madrid, 2002.

GÓMEZ DE LAS ROCES, H., «El futuro incierto del Estado», VV. AA., La reforma constitucional, Ministerio de Justicia, Madrid, 2005, pp. 69-82.

GONZÁLEZ ENCINAR, J. J., «La Constitución y su reforma», Revista Española de Derecho Constitucional, núm. 17, 1986, pp. 345-391.

HARO, J., «Sobre los límites materiales de la enmienda y la reforma constitucional», CARRASCO DURÁN, M., PÉREZ ROYO, J., URÍAS MARTÍNEZ, J. Y TEROL BECERRA, M. J., Derecho constitucional para el siglo XXI: actas del VIII Congreso Iberoamericano de Derecho Constitucional, Thompson-Aranzadi, Madrid, Vol. 1, 2006, pp. 255-286.

HERNÁNEZ VALLE, R., «El poder constituyente derivado y los límites jurídicos del poder de reforma constitucional», Revista Española de Derecho Constitucional, núm. 37, 1993 , pp. 143-155.

HERNÁNDEZ VALLE, R., «El control de constitucionalidad del procedimiento de reforma constitucional», Estudios constitucionales: Revista del Centro de Estudios Constitucionales, año 4, núm. 2, 2006, pp. 457-476.

HERRÁEZ VILAS, P., Proceso constituyente y reforma constitucional en la España del siglo XIX, Universitat de Barcelona, 1998.

JELLINEK, G., Reforma y mutación de la constitución, CEPC, Madrid, 1991 (Estudio Preliminar de P. Lucas Verdú).

JIMÉNEZ CAMPO, J., «Algunos problemas de interpretación en torno al Título X de la Constitución», Revista de Derecho Político, núm. 7, 1980, pp. 81-103.

LÓPEZ AGUILAR, J. F., «Los desafíos políticos de la reforma constitucional», VV. AA., La reforma constitucional, Ministerio de Justicia, Madrid, 2005, pp. 17-24.

LÓPEZ GUERRA, L. M., «La reforma constitucional: elementos formales y materiales», VV. AA., La reforma constitucional, Ministerio de Justicia, Madrid, 2005, pp. 515520.

MARTÍN OVIEDO, J. M., «Presentación del Informe», Revista española de la función consultiva, núm. 4, (Ejemplar dedicado a: Reforma de los Estatutos de Autonomía y Reforma de la Constitución), 2005, pp. 19-24.

MARTÍNEZ CUADRADO, M., «El espíritu de la Reforma Constitucional y el método filisteo de Contrarreforma», Cuenta y Razón, núm. 98, 1996, pp. 21-34.

MARTÍNEZ CUADRADO, M., "Límites constitucionales de la paz», Cuenta y Razón, núm. 108, 1998, pp. 7-21.

MORODO LEONCIO, R., «Las doctrinas políticas sobre la reforma constitucional», TIERNO GALVÁN, E., MORODO LEONCIO, R., Estudios de pensamiento político, Tucar Ediciones, Madrid, 1976, pp. 173-202.

NOGUEIRA ALCALÁ, H., «Consideraciones sobre poder constituyente y reforma de la Constitución en la Teoría y la práctica constitucional», Ius et Praxis, Vol. 15, núm. 1, 2009, pp. 229-262. 
PACE, A., VARELA SUANZES-CARPEGNA, J., La rigidez de las constituciones escritas, CEPC, Madrid, 1995.

PASCUCCI DE PONTE, E., «La Reforma de la Constitución: un estudio de Derecho Constitucional comparado», Saberes: Revista de estudios juridicos, económicos y sociales, núm. 1, 2003.

PECES-BARBA MARTÍNEZ, G., «Reflexiones sobre la reforma constitucional», VV. AA., La reforma constitucional, Ministerio de Justicia, Madrid, 2005, pp. $45-54$.

PÉREZ ROYO, J., «La reforma de la Constitución», Revista de Derecho Político, núm. 22, 1986, pp. 7-60.

PÉREZ ROYO, J., La reforma de la Constitución, Congreso de los Diputados, Madrid, 1987.

PÉREZ ROYO, J., «Algunas reflexiones sobre el Título X de la Constitución», Revista de Política Comparada, núms. 10-11, 1994, pp. 427-450.

PÉREZ ROYO, J., «Artículo 166: La iniciativa de la reforma», ALZAGA VILLAAMIL, O. (dir.), Comentarios a la Constitución Española de 1978, Cortes Generales, EDERSA, Madrid, 1999, Tomo XII, pp. 437-455.

PÉREZ ROYO, J., «Artículo 167: La reforma parcial de la Constitución», ALZAGA VILLAAMIL, O. (dir.), Comentarios a la Constitución Española de 1978, Cortes Generales, EDERSA, Madrid, 1999, Tomo XII, pp. 457-481.

PÉREZ ROYO, J., «Artículo 168: La revisión de la Constitución», ALZAGA VILLAAMIL, O. (dir.), Comentarios a la Constitución Española de 1978, Cortes Generales, EDERSA, Madrid, 1999, Tomo XII, pp. 483-505.

PÉREZ ROYO, J., "Artículo 169: Límites a la iniciativa de reforma», ALZAGA VILLAAMIL, O. (dir.), Comentarios a la Constitución Española de 1978, Cortes Generales, EDERSA, Madrid, 1999, Tomo XII, pp. 507-513.

PÉREZ ROYO, J., «De la reforma constitucional. Comentario introductorio al Título X», ALZAGA VILlAAMIL, O. (dir.), Comentarios a la Constitución Española de 1978, Cortes Generales, EDERSA, Madrid, 1999, Tomo XII, pp. 413-436.

PÉREZ ROYO, J., «Una asignatura pendiente: la reforma de la Constitución», Revista Española de Derecho Constitucional, núm. 69, 2003, pp. 215-235.

PÉREZ TREMPS, P., «La reforma de la Constitución veinticinco años después (la apertura del melón)», RAMIRO AVILÉS, M. A., PECES-BARBA MARTÍNEZ, G., La Constitución a examen: un estudio académico 25 años después, Marcial Pons, Madrid, 2004, pp. 793-808.

POSADA, A., La reforma constitucional, Ed. Victoriano Suárez, Madrid, 1931.

PUY MUÑOZ, F., «¿Reformamos la constitución?», BALADO RUIZ-GALLEGOS, M., GARCÍA REGUEIRO, J. A., La Constitución española de 1978 en su XXV aniversario, Bosch, Barcelona, 2003, pp. 1279-1284.

RAMÍREZ JIMÉNEZ, M., «Sugerencias ante una posible reforma constitucional», Cuadernos de pensamiento político FAES, núm. 19, 2008, pp. 137-148. 
REQUEJO PAGES, J. L., «El poder constituyente constituido: la limitación del soberano», Fundamentos. Cuadernos monográficos de Teoría del Estado, Derecho Público e Historia Constitucional (Ejemplar dedicado a: Soberanía y constitución), Vol. 1, 1998, pp. 361379.

REY MARTÍNEZ, F., «La reforma constitucional en España», Revista española de derecho constitucional, núm. 84, 2008, pp. 403-409.

RODRÍGUEZ GAONA, R., «¿Puede existir inconstitucionalidad en las normas reformatorias de la Constitución? La justicia constitucional y la validez de las normas jurídicas superiores», Derechos y libertades: Revista del Instituto Bartolomé de las Casas, núm. 10, 2001, pp. 169-198.

RODRÍGUEZ GAONA, R., El control constitucional de la reforma de la Constitución, Instituto Bartolomé de las Casas-Dykinson, Madrid, 2006.

RUBIO LLORENTE, F., «Sobre la conveniencia de terminar la Constitución antes de acometer su reforma», Claves de Razón Práctica, núm. 25, 1992, pp. 10-14.

RUBIO LLORENTE, F., «La necesidad de la reforma constitucional», VV. AA., La reforma constitucional, Ministerio de Justicia, Madrid, 2005, pp. 25-44.

RUIPÉREZ ALAMILLO, J., «Una cuestión actual en la discusión política española: la constitución española y las propuestas nacionalistas, o de los límites de la mutación y la reforma constitucional como instrumento para el cambio político», Civitas Europa, núm. 1, 1999, pp. 133-155.

RUIPÉREZ ALAMILLO, J., Proceso constituyente, soberanía y autodeterminación, Biblioteca Nueva, Madrid, 2003.

RUIPÉREZ ALAMILLO, J., «Estática y dinámica constitucionales en la España de 1978. Especial referencia a la problemática de los límites a los cambios constitucionales», ROURA GÓMEZ, S. A., TAJADURA TEJADA, J. (coords.), La reforma constitucional: la organización territorial del Estado, la Unión Europea y la igualdad de género, Biblioteca Nueva, Madrid, 2005, pp. 15-280.

SAGARRA RENEDO, P. L., La reforma silenciada: (una propuesta de reforma de la Constitución Española de 1978), Universa Terra, Salamanca, 2006.

SÁNCHEZ GONZÁLEZ, S., «Reforma, mutación y...quiebra constitucionales», Teoría y Realidad Constitucional, núm. 19, 2007, pp. 295-310.

SÁNCHEZ URRUTIA, A. V., «Mutación constitucional y fuerza normativa de la Constitución», Revista Española de Derecho Constitucional, núm. 58, 2000, pp. 105-135.

SANTAOLALLA LÓPEZ, F., «Artículo 166», «Artículo 167», «Artículo 168» y «Artículo 169», GARRIDO FALLA, F. (dir.), Comentarios a la Constitución, $3^{\mathrm{a}}$ ed., Civitas, Madrid, 2001, pp. 2709-2752.

SAUCA CANO, J. M., «La reforma de la reforma de la Constitución: el puzzle constitucional de Alf Ross», LAPORTA, F. J., (ed..), Constitución: problemas filosóficos, CEPC, Madrid, 2003, pp. 281-326.

TAJADURA TEJADA, J., «El Pacto social como límite a la reforma del acto constitucional», ROURA GÓMEZ, S. A., TAJADURA TEJADA, J. (coords.), La re- 
forma constitucional: la organización territorial del Estado, la Unión Europea y la igualdad de género, Biblioteca Nueva, Madrid, 2005, pp. 365-400.

TORRES FERNÁNDEZ. J., «Los derechos fundamentales como límite a la reforma constitucional», VV. AA., Introducción a los Derechos Fundamentales. X Jornadas de estudio, Ministerio de Justicia, Madrid, 1988, pp. 1273-1301.

TORRES DEL MORAL, A., «Valores y principios constitucionales», Revista de Derecho Político, núm. 36 (especial sobre La reforma constitucional), 1992, pp. 17-26.

TORRES DEL MORAL, A., «El instituto de la rigidez como garantía de la Constitución», Bazán, V., (coord.), Defensa de la Constitución: garantismo y controles: libro en reconocimiento al Dr. Germán Bidart Campos, Ediar, Buenos Aires, 2003, pp. 419-433.

VERA SANTOS, J. M., La reforma constitucional en España, La Ley-Wolters Kluwer, Madrid, 2007.

ZÚÑIGA URBINA, F., «Reforma constitucional: democracia y Estado de Derecho», CARRASCO DURÁN, M., PÉREZ ROYO, J., URÍAS MARTÍNEZ, J. Y TEROL BECERRA, M. J., Derecho constitucional para el siglo XXI: actas del VIII Congreso Iberoamericano de Derecho Constitucional, Thompson-Aranzadi, Madrid, Vol. 1, 2006, pp. 107-208.

\section{I.3. Algunos aspectos específicos de la ReForma CONSTitucional}

ASTOLA MADARIAGA, J., «La reforma de la Constitución española desde una perpectiva de género», ROURA GÓMEZ, S. A., TAJADURA TEJADA, J. (coords.), La reforma constitucional: la organización territorial del Estado, la Unión Europea y la igualdad de género, Biblioteca Nueva, Madrid, 2005, pp. 523-565.

BALAGUER CALLEJÓN, M. A., «La reforma constitucional en el derecho de sindicación y de huelga», Revista de Derecho Político, núm. 36 (especial sobre La reforma constitucional), 1992, pp. 193-206.

BASSOLS COMA, M., «La Constitución económica», Revista de Derecho Político, núm. 36 (especial sobre La reforma constitucional), 1992, pp. 277-290.

ESPEJO LERDO DE TEJADA, M., «Reforma constitucional de la legítima y problemas de derecho transitorio», Boletín de Información del Ministerio de Justicia, núm. 1748, 1995, pp. 3914-3949.

GARCIA HERRERA, M. A., «Rigidez constitucional y estado social», ANDRÉS IBÁÑEZ, P. (dir.), La experiencia jurisdiccional. del Estado legislativo de Derecho al Estado constitucional de Derecho, CGPJ, Madrid, 1999, pp. 33-88.

GÓMEZ SÁNCHEZ, Y., «La pena de muerte (Art. 15)», Revista de Derecho Político, núm. 36 (especial sobre La reforma constitucional), 1992, pp. 165-192.

GÓMEZ SÁNCHEZ, Y., «Matrimonio y familia: Arts. 32 y 39 de la Constitución», Revista de Derecho Político, núm. 36 (especial sobre La reforma constitucional), 1992, pp. 207-224. 
GÓMEZ SÁNCHEZ, Y., «El Tribunal de Cuentas (Art. 136)», Revista de Derecho Político, núm. 36 (especial sobre La reforma constitucional), 1992, pp. 291-300.

LAFUENTE BALLE, J. M., «Sobre el carácter taxativo o declarativo de la relación de las misiones atribuidas a las Fuerzas Armadas en el Art. 8 de la Constitución», Revista de Derecho Político, núm. 36 (especial sobre La reforma constitucional), 1992, pp. 65-72.

LUCAS MURILLO DE LA CUEVA, P., «La consolidación de un Estado de hecho y el problema de las disposiciones adicionales y transistorias», VV. AA., La reforma constitucional, Ministerio de Justicia, Madrid, 2005, pp. 371-398.

MONTALVO CORREA, J., «La Reforma del marco constitucional», VV.AA., Reforma laboral y negociación colectiva: VII Jornadas de Estudio sobre la Negociación Colectiva, Madrid, 9 de junio de 1994, Ministerio de Trabajo y Asuntos Sociales, Madrid, 1995, pp. 9-29.

MUÑOZ ARNAU, J. A., «Colegios y organizaciones profesionales», Revista de Derecho Político, núm. 36 (especial sobre La reforma constitucional), 1992, pp. 225-234.

PULIDO QUECEDO, M., «El inicio de la reforma constitucional (Sobre el documento del Gobierno)», Repertorio Aranzadi del Tribunal Constitucional, núm. 1, 2005, pp. $9-12$.

PULIDO QUECEDO, M., «¿Dónde queda la reforma constitucional?», Repertorio Aranzadi del Tribunal Constitucional, núm. 12, 2006, pp. 9-10.

RALLO LOMBARDE, A., «Iniciativa popular, estado autonómico y reforma constitucional», Revista Vasca de Administración Pública, núm. 50, 1998, pp. 205-223.

RAMÍREZ JIMÉNEZ, M., «El reforzamiento de la participación política», Revista de Derecho Político, núm. 36 (especial sobre La reforma constitucional), 1992, pp. 27-46.

REDONDO GARCÍA, A., «Algunas consideraciones en torno a la anunciada Reforma Constitucional», Parlamento y Constitución, núm. 8, 2004, pp. 139-152

RODRÍGUEZ, A., «El artículo 6 de la Constitución: los partidos políticos», Revista de Derecho Político, núm. 36 (especial sobre La reforma constitucional), 1992, pp. 47-64.

RUIPÉREZ ALAMILLO, J., «Algunas consideraciones sobre la reforma constitucional», Revista de Estudios Políticos, núm. 75, 1992, pp. 233-258.

RUIZ ROBLEDO, A., CÁMARA VILLAR, G., «Reflexiones sobre una hipotética reforma constitucional del Capítulo II del Título del Título I de la Constitución», Revista de Derecho Político, núm. 36 (especial sobre La reforma constitucional), 1992, pp. 129164.

SALVADOR MARTÍNEZ, M., «El Consejo de Estado ante la reforma constitucional», Teoría y realidad constitucional, núm. 16, 2005, pp. 467-486.

SÁNCHEZ FERRIZ, R., «Algunas reflexiones sobre la efectividad de los derechos y libertades», Revista de Derecho Político, núm. 36 (especial sobre La reforma constitucional), 1992, pp. 235-254.

SÁNCHEZ GONZÁLEZ, S., PEREIRA MENAUT, A. C., «Los derechos sociales y los principios rectores de la política social y económica», Revista de Derecho Político, núm. 36 (especial sobre La reforma constitucional), 1992, pp. 257-276. 
VENTURA FRANCH, A., «Igualdad real y reforma constitucional», FREIXES SANJUÁN, T., SEVILLA MERINO, T., Género, constitución y estatutos de autonomía, INAP, Madrid, 2005, pp. 267-280.

VIDAL FUEYO, M. C., «Al hilo de la reforma constitucional: los problemas de interpretación que genera la expresión libertades públicas en la Constitución española», Parlamento y Constitución, núm. 8, 2004, pp. 153-168.

\section{ESTUDIOS SOBRE LA REFORMA DE ÓRGANOS CONSTITUCIONALES}

\section{II.1. LA REFORMA DE LA CORONA}

BELDA PÉREZ-PEDRERO, E., «Reforma constitucional y sucesión», ÁLVAREZ JUNCO, J., RUBIO LLORENTE, F. (eds.), El informe del Consejo de Estado sobre la reforma constitucional: texto del informe y debates académicos, CEPC y Consejo de Estado, Madrid, 2006, pp. 273-295.

DOMÍNGUEZ-BERRUETA DE JUAN, M. A., SENDÍN GARCÍA, M. A., «La igualdad de sexos y el acceso a la Corona», VV. AA., La reforma constitucional, Ministerio de Justicia, Madrid, 2005, pp. 499-512.

ELÍAS DE TEJADA CASANOVA, J. M., «Comentario sobre la influencia de la reforma de la Constitución en la sucesión de los títulos nobiliarios», VV. AA., La reforma constitucional, Ministerio de Justicia, Madrid, 2005, pp. 485-498.

FERNÁNDEZ CAMPO, S., «En torno a una posible reforma constitucional: la supresión del actual preferencia del varón sobre la mujer en la sucesión a la Corona», Anales de la Real Academia de Ciencias Morales y Políticas, núm. 83, 2006, pp. 435-448.

FERNANDEZ DE LA MORA, G., «Ante la reforma constitucional», VV. AA., La Corona y la nueva sociedad española ante un año bistórico : ciclo de conferencias pronunciadas en el Club Siglo XXI durante el curso 1976-1977, Fomento Editorial, Madrid, 1977, Vol. II, pp. 413-424.

FERNÁNDEZ-FONTECHA TORRES, M., «Algunos problemas derivados de la posible reforma del artículo 57.1 de la Constitución», ÁLVAREZ JUNCO, J., RUBIO LLORENTE, F. (eds.), El informe del Consejo de Estado sobre la reforma constitucional: texto del informe y debates académicos, CEPC y Consejo de Estado, Madrid, 2006, pp. 297-306.

FREIXES SANJUÁN, T., «Reforma de la Constitución: igualdad de mujeres y hombres y sucesión a la Corona de España», ÁLVAREZ JUNCO, J., RUBIO LLORENTE, F. (eds.), El informe del Consejo de Estado sobre la reforma constitucional: texto del informe y debates académicos, CEPC y Consejo de Estado, Madrid, 2006, pp. 307-364.

GARCÍA TORRES, J., «Consideraciones sobre la posible reforma del Derecho dinástico constitucional», VV. AA., La reforma constitucional, Ministerio de Justicia, Madrid, 2005, pp. 427-454. 
GÓMEZ SÁNCHEZ, Y., «La sucesión a la Corona: la reforma del artículo 57.1 de la Constitución española», FREIXES SANJUÁN, T., SEVILLA MERINO, T., Género, constitución y estatutos de autonomía, INAP, Madrid, 2005, pp. 181-203.

GÓMEZ SÁNCHEZ, Y., «La sucesión a la Corona: la reforma del artículo 57.1 de la Constitución española», ÁLVAREZ JUNCO, J., RUBIO LLORENTE, F. (eds.), El informe del Consejo de Estado sobre la reforma constitucional: texto del informe y debates académicos, CEPC y Consejo de Estado, Madrid, 2006, pp. 365-401.

LAFUENTE BALLE, J. M., «De cómo opera en la práctica el Mando Militar del Rey», Revista de Derecho Político, núm. 36 (especial sobre La reforma constitucional), 1992, pp. 321-332.

OLIVER ARAUJO, J., «La reforma constitucional de la Corona: (una propuesta radical y diez moderadas)», Revista de Derecho Político, núm. 77, 2010, pp. 13-69

PEMÁN MEDINA, P., «La sucesión a la Corona y su repercusión en la sucesión en los títulos nobiliarios», VV. AA., La reforma constitucional, Ministerio de Justicia, Madrid, 2005, pp. 465-472.

REQUEJO ALEMÁN, J. L., «Límites constitucionales a la reforma de la Corona», VV. AA., La reforma constitucional, Ministerio de Justicia, Madrid, 2005, pp. 455-464.

REY MARTÍNEZ, F., «Derecho de sucesión en la Corona y discriminación por razón de sexo: análisis de la posible supresión de la preferencia sucesoria de los varones (art. 57.1 de la Constitución española)», ÁLVAREZ JUNCO, J., RUBIO LLORENTE, F. (eds.), El informe del Consejo de Estado sobre la reforma constitucional: texto del informe y debates académicos, CEPC y Consejo de Estado, Madrid, 2006, pp. 403-441.

TORRE DE SILVA y LÓPEZ DE LETONA, J., «Comentario sobre la sucesión en la Corona y su repercusión en la sucesión en los títulos nobiliarios», VV. AA., La reforma constitucional, Ministerio de Justicia, Madrid, 2005, pp. 473-484.

TORRES DEL MORAL, A., «La Corona», Revista de Derecho Político, núm. 36 (especial sobre La reforma constitucional), 1992, pp. 303-320.

TORRES DEL MORAL, A., «Reforma constitucional de la sucesión en la Corona», Revista española de la función consultiva, núm. 4, (Ejemplar dedicado a: Reforma de los Estatutos de Autonomía y Reforma de la Constitución), 2005, pp. 25-34.

TORRES DEL MORAL, A., «Reforma constitucional de la sucesión en la Corona», ÁLVAREZ JUNCO, J., RUBIO LLORENTE, F. (eds.), El informe del Consejo de Estado sobre la reforma constitucional: texto del informe y debates académicos, CEPC y Consejo de Estado, Madrid, 2006, pp. 443-453.

\section{II.2. LA REFORMA CONSTITUCiONAL DEL SENADO}

AGAPITO SERRANO, R., «Presupuestos constitucionales de la integración de las Comunidades Autónomas en la orgánica del Estado: la reforma del Senado», GARCÍA HERRERA, M. A., VIDAL BELTRÁN, J. M., El Estado Autonómico: integración, solidaridad, diversidad, Colex, INAP, Madrid, 2005, Vol. 1, pp. 213-228. 
AJA FERNÁNDEZ, E., «Principales líneas de la reforma constitucional del Senado», Autonomies, núm. 20, 1995, pp. 51-60.

AJA FERNÁNDEZ, E., «El hecho diferencial en la reforma constitucional del Senado», TORRES AGUILAR, M. (coord.), El Senado: ¿Cámara de representación territorial?, Diputación de Córdoba, 2001, pp. 90-108.

AJA FERNÁNDEZ, E., «La reforma constitucional del Senado para convertirlo en una cámara autonómica», AJA FERNÁNDEZ, E., ALBERTÍ ROVIRA, E. y RUIZ RUIZ, J. J., La reforma constitucional del Senado, CEPC, Madrid, 2005, pp. 11-32.

AJA FERNÁNDEZ, E., «La reforma constitucional del Senado, clave del futuro autonómico», VALLS-LLOBET, C., DONALDSON, M., Hacia una España plural, social y federal, Ed. Mediterrània, Barcelona, 2005, pp. 247-253.

AJA FERNÁNDEZ, E., «La reforma constitucional del Senado: hacia una cámara autonómica designada por los gobiernos», ÁLVAREZ JUNCO, J., RUBIO LLORENTE, F. (eds.), El informe del Consejo de Estado sobre la reforma constitucional: texto del informe y debates académicos, CEPC y Consejo de Estado, Madrid, 2006, pp. 709-731.

ALBA NAVARRO, M., "Diversos modelos para la reforma del Senado», PAU I VALL, F. (coord.), El Senado, Cámara de representación territorial: III Jornadas de la Asociación Española de Letrados de Parlamentos, Tecnos, Madrid, 1996, pp. 227-238.

ALBERTÍ ROVIRA, E., «La reforma constitucional del Senado», VV. AA., La reforma constitucional, Ministerio de Justicia, Madrid, 2005, pp. 99-108.

ALBERTÍ ROVIRA, E., «La reforma constitucional del Senado a la hora de la verdad», AJA FERNÁNDEZ, E., ALBERTÍ ROVIRA, E. y RUIZ RUIZ, J. J., La reforma constitucional del Senado, CEPC, Madrid, 2005, pp. 33-50.

ALONSO DE ANTONIO, J., «Algunas propuestas para la reforma constitucional del Senado», Revista de ciencias jurídicas y sociales, núm. 2, 2005, pp. 359-407.

ALONSO DE ANTONIO, J., «La función legislativa del nuevo Senado (apuntes para una reforma constitucional)», VV. AA., Estudios sobre la Constitución Española: homenaje al profesor Jordi Solé Tura, Congreso de los Diputados, Madrid, 2008, Vol. 1, pp. 311326.

ARBÓS, X, «El Senado. Marco constitucional y propuestas de reforma», Revista de las Cortes Generales, núm. 24, 1992, pp. 7-33.

BASTIDA FREIJEDO, F. J., «La reforma del Senado en el Dictamen del Consejo de Estado», Revista española de la función consultiva, núm. 4, (Ejemplar dedicado a: Reforma de los Estatutos de Autonomía y Reforma de la Constitución), 2005, pp. 79-90.

BIGLINO CAMPOS, P., «El Senado, cámara de conexión entre las Comunidades Autónomas y la Unión Europea», ÁLVAREZ JUNCO, J., RUBIO LLORENTE, F. (eds.), El informe del Consejo de Estado sobre la reforma constitucional: texto del informe y debates académicos, CEPC y Consejo de Estado, Madrid, 2006, pp. 733-750.

BILBAO ARRESE, J., «La reforma constitucional de la composición del Senado», Revista de las Cortes Generales, núm. 33, 1994, pp. 185-197. 
CAAMAÑO DOMÍNGUEZ, F. M., «La reforma del Senado», VV. AA., La reforma constitucional, Ministerio de Justicia, Madrid, 2005, pp. 91-98.

CARBONELL SÁNCHEZ, M., «Sobre la reforma constitucional y sus funciones», MORODO LEONCIO, R., DE VEGA, P. (coord.), Estudios de teoría del Estado y derecho constitucional en honor de Pablo Lucas Verdú, Universidad Complutense de Madrid, 2001, Vol. 2, pp. 851-874.

CHUECA RODRÍGUEZ, R. L., «Condicionamientos constitucionales de la reforma del Senado», GARCÍA HERRERA, M. A., VIDAL BELTRÁN, J. M., El Estado Autonómico: integración, solidaridad, diversidad, Colex, INAP, Madrid, 2005, Vol. 1, pp. 199-212.

COELLO DE PORTUGAL y MARTÍNEZ DEL PERAL, I., «Comentario sobre la reforma del Senado», VV. AA., La reforma constitucional, Ministerio de Justicia, Madrid, 2005, pp. 131-138.

DE MIGUEL BÁRCENA, J., «La reforma constitucional del Senado ante la Unión Europea», GARCÍA HERRERA, M. A., VIDAL BELTRÁN, J. M., El Estado Autonómico: integración, solidaridad, diversidad, Colex, INAP, Madrid, 2005, Vol. 2, pp. 409-426.

FERNÁNDEZ SEGADO, F. «Reflexiones en torno a la reforma constitucional del Senado», Revista de Derecho Político, núm. 42, 1996, pp. 35-53.

FERNÁNDEZ-MIRANDA CAMPOAMOR, A., «Sobre la reforma del Senado», ÁlVAREZ JUNCO, J., RUBIO LLORENTE, F. (eds.), El informe del Consejo de Estado sobre la reforma constitucional: texto del informe y debates académicos, CEPC y Consejo de Estado, Madrid, 2006, pp. 751-794.

FERRI DURA, J., «La actitud de los partidos ante la reforma del Senado», PAU I VALL, F. (coord.), El Senado, Cámara de representación territorial: III Jornadas de la Asociación Española de Letrados de Parlamentos, Tecnos, Madrid, 1996, pp. 305-316.

GARCÍA-ESCUDERO MÁRQUEZ, P. A., «Vueltas con la reforma constitucional del Senado: de las opciones a las decisiones», Teoría y realidad constitucional, núm. 17 (Ejemplar dedicado a: El Senado), 2006, pp. 195-222.

GARCÍA-ESCUDERO MÁRQUEZ, P., «La reforma constitucional del Senado: cuestiones a resolver», ÁLVAREZ JUNCO, J., RUBIO LLORENTE, F. (eds.), El informe del Consejo de Estado sobre la reforma constitucional: texto del informe y debates académicos, CEPC y Consejo de Estado, Madrid, 2006, pp. 795-824.

GARRORENA MORALES, A., «La Reforma constitucional del Senado», ÁLVAREZ JUNCO, J., RUBIO LLORENTE, F. (eds.), El informe del Consejo de Estado sobre la reforma constitucional: texto del informe y debates académicos, CEPC y Consejo de Estado, Madrid, 2006, pp. 897-929.

GARRORENA MORALES, A., «Una propuesta para la reforma constitucional del Senado», Revista de las Cortes Generales, núm. 34, 1995, pp. 7-49.

GOIZUETA VERTIZ, J., ZELAIA GARAGARZA, M., «Algunas consideraciones en torno a la composición y funciones del Senado : problemas suscitados y reformas propuestas», Revista Vasca de Administración Pública, núm. 50, 1998, pp. 369-392. 
GONZÁLEZ-TREVIJANO SÁNCHEZ, P. J., «Una reforma constitucional del Senado o «Una cámara en busca de autor «», ÁLVAREZ JUNCO, J., RUBIO LLORENTE, F. (eds.), El informe del Consejo de Estado sobre la reforma constitucional: texto del informe y debates académicos, CEPC y Consejo de Estado, Madrid, 2006, pp. 825-841.

GRAU RUIZ, M. A., «El papel del Senado en la financiación de las Comunidades Autónomas», VV. AA., La reforma constitucional, Ministerio de Justicia, Madrid, 2005, pp. 153-168.

LLERA RAMO, F. J., «Escenarios para una reforma en la composición y elección del Senado español», ÁLVAREZ JUNCO, J., RUBIO LLORENTE, F. (eds.), El informe del Consejo de Estado sobre la reforma constitucional: texto del informe y debates académicos, CEPC y Consejo de Estado, Madrid, 2006, pp. 843-855.

LÓPEZ GARRIDO, D., «Hacia un nuevo Senado: propuesta de reforma constitucional», Revista de las Cortes Generales, núm. 33, 1994, pp. 7-25.

MARTÍNEZ SOSPEDRA, M., «Los obstáculos a la reforma del Senado: falsos y verdaderos», Revista de Derecho Político, núm. 36 (especial sobre La reforma constitucional), 1992, pp. 377-398.

OTERO NOVAS, J. M., «Comentario sobre la reforma del Senado», VV. AA., La reforma constitucional, Ministerio de Justicia, Madrid, 2005, pp. 109-130.

PAU I VALL, F., «El Senado y el Estado plurinacional. Una reflexión desde Cataluña», PAU I VALL, F. (coord.), El Senado, Cámara de representación territorial: III Jornadas de la Asociación Española de Letrados de Parlamentos, Tecnos, Madrid, 1996, pp. 387-393.

PÉREZ TREMPS, P., «La reforma del Senado ante la Unión Europea», VV. AA., Ante el futuro del Senado, Institut d'Estudis Autonòmics, Barcelona,1996, pp. 433-450.

PÉREZ-SERRANO JÁUREGUI, N., «Reforma y Constitución», PAU I VALL, F. (coord.), El Senado, Cámara de representación territorial: III Jornadas de la Asociación Española de Letrados de Parlamentos, Tecnos, Madrid, 1996, pp. 217-226.

PORTERO MOLINA, J. A., «Sobre la reforma constitucional del Senado», ASENSI SABATER, J., Ciudadanos e instituciones en el constitucionalismo actual, Tirant, Valencia, 1996, pp. 65-96.

PORTERO MOLINA, J., «Contribución al debate sobre la reforma del Senado», Revista de Estudios Políticos, núm. 87, 1995, pp. 81-105.

PUNSET BLANCO, R., «De un Senado a otro: Reflexiones propuestas para la reforma constitucional», ÁLVAREZ JUNCO, J., RUBIO LLORENTE, F. (eds.), El informe del Consejo de Estado sobre la reforma constitucional: texto del informe y debates académicos, CEPC y Consejo de Estado, Madrid, 2006, pp. 857-896.

PUNSET BLANCO, R., «La territorialización del Senado y la reforma de la Constitución», Revista Española de Derecho Constitucional, núm. 37, 1993, pp. 81-90.

RÍOS RULL, F., «Alternativas a la reforma constitucional del Senado», ÁLVAREZ DE LA ROSA, M., HERNÁNDEZ BRAVO DE LAGUNA, J., Estudios sobre la constitución española : libro homenaje a Gumersindo Trujillo Fernández, Universidad de La Laguna, 2006, pp. 507-518. 
RIPOLLÉS SERRANO, M. R., «La reforma del Senado: Senado y Estado Autonómico 1978-2004», VV. AA., La reforma constitucional, Ministerio de Justicia, Madrid, 2005, pp. 169-186.

RODRÍGUEZ-ARANA MUÑOZ, J., «El Senado y las cuestiones territoriales», VV. AA., La reforma constitucional, Ministerio de Justicia, Madrid, 2005, pp. 187-204.

ROJO, J., «El Senado: de la Constitución a la necesaria reforma», BALADO RUIZ-GALLEGOS, M., La España de las autonomías: reflexiones 25 años después, Bosch, Barcelona, 2005, pp. 35-40.

ROURA GÓMEZ, S. A., «La reforma constitucional del Senado en la VIII Legislatura», ROURA GÓMEZ, S. A., TAJADURA TEJADA, J. (coords.), La reforma constitucional: la organización territorial del Estado, la Unión Europea y la igualdad de género, Biblioteca Nueva, Madrid, 2005, pp. 337-364.

RUBIO LLORENTE, F., «La reforma constitucional del Senado», VV. AA., Ante el futuro del Senado, Institut d'Estudis Autonòmics, Barcelona,1996, pp. 357-364.

RUIZ RUIZ, J. J., «La reforma constitucional del Senado en España. Adecuación a los principios de forma de gobierno parlamentaria bicameral», RUIZ-RICO RUIZ, G. J., GAMBINO, S., Formas de gobierno y sistemas electorales: la experiencia italiana y española, Universidad de Jaén / Tirant Lo Blanch, Valencia, 1997, pp. 331-395.

RUIZ RUIZ, J. J., «La reforma Constitucional del Senado en España y la asimetría del Estado Autonómico: la igualdad en la representación de las Nacionalidades y Regiones», PAU I VALL, F. (coord.), El Senado, Cámara de representación territorial: III Jornadas de la Asociación Española de Letrados de Parlamentos, Tecnos, Madrid, 1996, pp. 395-410.

RUIZ RUIZ, J. J., «Tipología y praxis del veto territorial contra las decisiones de la mayoría en el Derecho Comparado: aportaciones al debate en torno a la inclusión de un veto de las Comunidades Autónomas en el Senado», VV. AA., La reforma constitucional, Ministerio de Justicia, Madrid, 2005, pp. 205-250.

RUIZ RUIZ, J., «Límites materiales a la reforma constitucional del Senado en España: una lectura desde el «patrimonio común europeo» de la reforma de gobierno parlamentaria», Parlamento y Constitución, núm. 8, 2004, pp. 73-100.

RUIZ RUIZ, J. J., «Democracia mayoritaria e integración de los intereses territoriales en el Senado: (comentario a la ponencia del prof. Eliseo Aja sobre la reforma del Senado)», AJA FERNÁNDEZ, E., ALBERTÍ ROVIRA, E. y RUIZ RUIZ, J. J., La reforma constitucional del Senado, CEPC, Madrid, 2005, pp.51-68.

SÁNCHEZ MANZANO, M., «Perspectivas para la reforma constitucional del Senado», PAU I VALL, F. (coord.), El Senado, Cámara de representación territorial: III Jornadas de la Asociación Española de Letrados de Parlamentos, Tecnos, Madrid, 1996, pp. 339-352.

SENADO, Ponencia de estudio de la reforma constitucional de senado: Comparecencias ante la Ponencia de Estudio de la Reforma Constitucional del Senado, Madrid, 1995.

TOMÁS y VALIENTE, F., «La posible configuración del Senado», PAU I VALL, F. (coord.), El Senado, Cámara de representación territorial: III Jornadas de la Asociación Española de Letrados de Parlamentos, Tecnos, Madrid, 1996, pp. 367-374. 
TORRES DEL MORAL, A., «El Senado», Revista de Derecho Político, núm. 36 (especial sobre La reforma constitucional), 1992, pp. 357-376.

TRUJILLO, G., «La reforma constitucional y la participación del Senado en las relaciones de colaboración entre el Estado y las comunidades autónomas», VV. AA., Ante el futuro del Senado, Institut d'Estudis Autonòmics, Barcelona,1996, pp. 377-392.

TRUJILLO, G., «Nuevas consideraciones sobre la reforma constitucional del Senado», Cuadernos de Alzate: revista vasca de la cultura y las ideas, núm. 16, 1997, pp. 7994.

VV. AA., Dossier de prensa sobre las comparecencias efectuadas ante la Ponencia de Estudio para la Reforma Constitucional del Senado por los Ponentes de la Constitución y por los Presidentes de las Comunidades Autónomas, Dossier núm. 19 (Nueva Época), Dirección de Estudios y Documentación del Senado, Madrid, 1995.

\section{II.3. OTROS ÓRGANOS CONSTITUCIONALES}

APARICIO PÉREZ, M. A., «El Poder Judicial», Revista de Derecho Político, núm. 37 (especial sobre La reforma constitucional), 1992, pp. 161-176.

BAR CENDÓN, A., «Sobre una hipotética reforma del Título IV («Del Gobierno y de la Administración «) de la Constitución de 1978», Revista de Derecho Político, núm. 37 (especial sobre La reforma constitucional), 1992, pp. 11-34.

BAR CENDÓN, A., «Sobre una hipotética reforma de la potestad de disolución de las Cámaras legislativas prevista en el artículo 115 de la Constitución», Revista de Derecho Político, núm. 37 (especial sobre La reforma constitucional), 1992, pp. 149-158,

CRESPO HELLÍN, F., «El artículo 104 de la Constitución y la nueva regulación de la institución policial: sus disfuncionalidades», Revista de Derecho Político, núm. 37 (especial sobre La reforma constitucional), 1992, pp. 109-136.

FERNÁNDEZ-MIRANDA CAMPOAMOR, A., «Las Cortes Generales (Título III, Capítulo I)», Revista de Derecho Político, núm. 36 (especial sobre La reforma constitucional), 1992, pp. 335-346.

GARCÍA CUADRADO, A. M., «Las disposiciones del Gobierno y la Administración», Revista de Derecho Político, núm. 37 (especial sobre La reforma constitucional), 1992, pp. 93-108.

GARCÍA-ATANCE GARCÍA DE MORA, M. V., «La indelegabilidad del voto y la Junta de Portavoces», Revista de Derecho Político, núm. 36 (especial sobre La reforma constitucional), 1992, pp. 399-406.

GERPE LANDÍN, M., «El Consejo General del Poder Judicial», Revista de Derecho Político, núm. 37 (especial sobre La reforma constitucional), 1992, pp. 177-188.

HERNANDO GARCÍA, P. J., «El estatuto jurídico de los miembros del Gobierno (Arts. 98.3 y 4)», Revista de Derecho Político, núm. 37 (especial sobre La reforma constitucional), 1992, pp. 35-50. 
MARTÍN REBOLLO, L., «La Administración en la Constitución (Arts. 103 a 107)», Revista de Derecho Político, núm. 37 (especial sobre La reforma constitucional), 1992, pp. 51-82.

MELLADO PRADO, P., «La responsabilidad política del Gobierno», Revista de Derecho Político, núm. 37 (especial sobre La reforma constitucional), 1992, pp. 139-148.

SÁNCHEZ NAVARRO, A., Consejo de Estado, función consultiva y reforma constitucional, Reus, Madrid, 2007.

SUAY RINCÓN, J., «Reflexiones sobre la posición de la Administración Pública en la Constitución Española de 1978: En particular, comentarios a los artículos 103.1 y 106.1 de la Constitución», Revista de Derecho Político, núm. 37 (especial sobre La reforma constitucional), 1992, pp. 83-92.

TENORIO SÁNCHEZ, P. J., «El Tribunal Constitucional», Revista de Derecho Político, núm. 37 (especial sobre La reforma constitucional), 1992, pp. 289-300.

TORRES DEL MORAL, A., «Reflexión sobre algunos preceptos del Título III, del Capítulo I», Revista de Derecho Político, núm. 36 (especial sobre La reforma constitucional), 1992, pp. 347-356.

\section{COMUNIDADES AUTÓNOMAS Y REFORMA CONSTITUCIONAL}

ACOSTA SÁNCHEZ, J., «Reforma y límites del Estado Autonómico», GARCÍA HERRERA, M. A., VIDAL BELTRÁN, J. M., El Estado Autonómico: integración, solidaridad, diversidad, Colex, INAP, Madrid, 2005, Vol. 2, pp. 131-144.

AGIRREAZKUENAGA ZIGORRAGA, I., «La reforma del Estatuto de Autonomía del País Vasco», VV. AA., La reforma constitucional, Ministerio de Justicia, Madrid, 2005, pp. 289-312.

ALONSO DE ANTONIO, J. A., FALCÓN y TELlA, R., ÁlVAREZ CONDE, E., «El Estado Autonómico (Título VIII)», Revista de Derecho Político, núm. 37 (especial sobre La reforma constitucional), 1992, pp. 191-262.

ÁLVAREZ VÉLEZ, M. I., ALCÓN YUSTAS, M. F., «Una visión sobre la posible reforma del Título VIII de la Constitución española de 1978», Parlamento y Constitución, núm. 8, 2004, pp. 39-50.

ARGULLOL I MURGADAS, E., «Constitución, Estatuto de autonomía, reforma, revisión y derechos históricos», VV. AA., Concordia civil en Euskadi: estrategias para la paz, Icaria, Barcelona, 2004, pp. 113-151.

BALAGUER CALLEJÓN, F., «Reformas constitucionales relativas al título VIII en relación con la recepción constitucional de la denominación oficial de las CCAA», ÁLVAREZ JUNCO, J., RUBIO LLORENTE, F. (eds.), El informe del Consejo de Estado sobre la reforma constitucional: texto del informe y debates académicos, CEPC y Consejo de Estado, Madrid, 2006, pp. 565-583. 
BALAGUER CALLEJÓN, M ${ }^{a}$ L., «Reforma Estatutaria y Reforma Constitucional», GARCÍA HERRERA, M. A., VIDAL BELTRÁN, J. M., El Estado Autonómico: integración, solidaridad, diversidad, Colex, INAP, Madrid, 2005, Vol. 2, pp. 251-256.

BALLESTER CARDELL, M., «Reformas estatuarias y descentralización de la Administración de Justicia», VV. AA., La reforma constitucional, Ministerio de Justicia, Madrid, 2005, pp. 323-336.

BIGLINO CAMPOS, P., «Reforma de la Constitución, reforma de los Estatutos de Autonomía y configuración constitucional del Orden de Competencias», Revista de las Cortes Generales, núm. 65, 2005, pp. 7-30.

CAAMAÑO DOMÍNGUEZ, F., «Las necesidades de Reforma Constitucional y estatutarias del estado autonómico», VV. AA., Reformas territoriales, Ed. Pablo Iglesias, Madrid, 2006, pp. 128-138.

CALAFELL FERRÁ, V. J., «Reforma constitucional, reforma estatuaria y colaboración entre Comunidades Autónomas», VV. AA., La reforma constitucional, Ministerio de Justicia, Madrid, 2005, pp. 337-350.

CARRERAS SERRA, F., «La inclusión de la denominación de las comunidades autónomas en la Constitución», ÁLVAREZ JUNCO, J., RUBIO LLORENTE, F. (eds.), El informe del Consejo de Estado sobre la reforma constitucional: texto del informe y debates académicos, CEPC y Consejo de Estado, Madrid, 2006, pp. 653-663.

CARRILLO, M., «Constitución, autogobierno y Euskadi», VV. AA., Concordia civil en Euskadi: estrategias para la paz, Icaria, Barcelona, 2004, pp. 245-276.

COLLADO YURRITA, M. A., «El sistema de financiación de las Comunidades Autónomas en la Constitución», Revista de Derecho Político, núm. 37 (especial sobre La reforma constitucional), 1992, pp. 263-272.

FELIÚ TORRENT, M. D., «Comentario sobre la reforma de los Estatutos de Autonomía», VV. AA., La reforma constitucional, Ministerio de Justicia, Madrid, 2005, pp. 317-322.

FERNÁNDEZ ALLES, J., «La reforma constitucional: hacia un régimen competencial sistematizado», Parlamento y Constitución, núm. 8, 2004, pp. 51-72.

FERNÁNDEZ RODRÍGUEZ, T., «De la reforma de los Estatutos a la reforma de la Constitución», Revista de ciencias jurídicas y sociales, núm. 5, 2007, pp. 13-28.

FERNÁNDEZ, A., ARIAS, F., LÓPEZ, P., «Reflexiones en torno a la reforma de los Estatutos de Autonomía. Puntos abiertos al debate», GARCÍA HERRERA, M. A., VIDAL BELTRÁN, J. M., El Estado Autonómico: integración, solidaridad, diversidad, Colex, INAP, Madrid, 2005, Vol. 2, pp. 613-638.

FOSSAS ESPADALER, E., «Reforma constitucional y reformas estatutarias: la denominación de las Comunidades Autónomas y el principio dispositivo», RUIZ-RICO RUIZ, G. J., La reforma de los Estatutos de Autonomía : actas del IV Congreso de la Asociación de Constitucionalistas de España, Tirant, Valencia, 2006, pp. 101-126.

FOSSAS ESPADALER, E., «La inclusión de la denominación de las Comunidades Autónomas en la Constitución: el jurista persa satisface (parcialmente) su curiosidad», ÁLVAREZ JUNCO, J., RUBIO LLORENTE, F. (eds.), El informe del Consejo de Estado so- 
bre la reforma constitucional: texto del informe y debates académicos, CEPC y Consejo de Estado, Madrid, 2006, pp. 585-608.

GARCÍA ÁLVAREZ, J., «Informe geográfico-histórico sobre la denominación de las entidades territoriales subestatales en la España constitucional (ss. XIX-XX)», ÁLVAREZ JUNCO, J., RUBIO LLORENTE, F. (eds.), El informe del Consejo de Estado sobre la reforma constitucional: texto del informe y debates académicos, CEPC y Consejo de Estado, Madrid, 2006, pp. 665-705.

GARCÍA-MONCÓ MARTÍNEZ, A., «La penúltima reforma del modelo de financiación autonómica. Problemas y desafíos», Revista española de la función consultiva, núm. 4, (Ejemplar dedicado a: Reforma de los Estatutos de Autonomía y Reforma de la Constitución), 2005, pp. 161-180.

JÁUREgUi BERECIARTU, G., «La inserción de la Comunidad Autónoma del País Vasco en entidades superiores: Estado español y Unión Europea», VV. AA., Concordia civil en Euskadi: estrategias para la paz, Icaria, Barcelona, 2004, pp. 277-316.

LÓPEZ-MEDEL BASCONES, J., «El impacto imprescindible en el desarrollo territorial del Estado», VV. AA., La reforma constitucional, Ministerio de Justicia, Madrid, 2005, pp. 83-90.

MARTÍN DELGADO, I., «Reforma Constitucional y Reforma Estatutaria», Revista de administración pública, núm. 169, 2006, pp. 486-490.

MARTÍN REBOLLO, L., «Consideraciones sobre la reforma de los Estatutos de Autonomía de las Comunidades Autónomas», VV. AA., La reforma constitucional, Ministerio de Justicia, Madrid, 2005, pp. 269-288.

MEDINA GUERRERO, M., «La inclusión de las Comunidades Autónomas-y ciudades autónomas - en el texto constitucional (o sobre la conveniencia de preservar el principio dispositivo en la concreción de la denominación de las Comunidades Autónomas)», ÁLVAREZ JUNCO, J., RUBIO LLORENTE, F. (eds.), El informe del Consejo de Estado sobre la reforma constitucional: texto del informe y debates académicos, CEPC y Consejo de Estado, Madrid, 2006, pp. 609-626.

MERINO MERCHÁN, J., «Reforma constitucional y reformas estatutarias», Revista de las Cortes Generales, núm. 66, 2005, pp. 405-414.

PÉREZ TREMPS, P., «¿Reforma del título IX de la Constitución?: El Tribunal Constitucional: organización y funcionamiento», Revista de Derecho Político, núm. 37 (especial sobre La reforma constitucional), 1992, pp. 275-288.

PORRAS NADALES, A. J., «El Estado autonómico y la reforma de la Constitución», Revista de Fomento Social, Vol. 54, núm. 213, 1999, pp. 25-45.

PORRAS RAMÍREZ, J. M., «El autogobierno local en el Estado Autonómico. Premisas para una reforma necesaria», GARCÍA HERRERA, M. A., VIDAL BELTRÁN, J. M., El Estado Autonómico: integración, solidaridad, diversidad, Colex, INAP, Madrid, 2005, Vol. 1, pp. 583-604.

PORTERO MOLINA, J. A., «El Estado de las Autonomías en tiempos de reformas», GARCÍA HERRERA, M. A., VIDAL BELTRÁN, J. M., El Estado Autonómico: integración, solidaridad, diversidad, Colex, INAP, Madrid, 2005, Vol. 2, pp. 39-64. 
RECODER VALLINA T., «¿Reforma Estatutaria o Reforma Constitucional? (Sobre la ATC de 15 de marzo de 2006)», Repertorio Aranzadi del Tribunal Constitucional, núm. 4, 2006, pp. 11-28.

RUIZ SOROA, J., «Reforma estatutaria o reforma constitucional», Cuadernos de Alzate: revista vasca de la cultura y las ideas, núm. 35, 2006, pp. 35-50.

SÁNCHEZ BLANCO, A., «La reforma del Estatuto de Autonomía de Andalucía», VV. AA., La reforma constitucional, Ministerio de Justicia, Madrid, 2005, pp. 351-370.

SÁNCHEZ DE LEÓN, P., «Reformas territoriales en España: ¿una reforma constitucional encubierta?», Revista valenciana d'estudis autonòmics, No 47-48, 2005, pp. 113121.

SARDINA PÁRAMO, J. A., «Reforma constitucional y Derecho Foral», VV. AA., La reforma constitucional, Ministerio de Justicia, Madrid, 2005, pp. 405-423.

SERRERA CONTRERAS, P. L., «Comentario sobre la reforma de los Estatutos de Autonomía», VV. AA., La reforma constitucional, Ministerio de Justicia, Madrid, 2005, pp. 313-316.

TAJADURA TEJADA, J., «La constitucionalización del mapa autonómico: una reforma necesaria, pero insuficiente», ROURA GÓMEZ, S. A., TAJADURA TEJADA, J. (coords.), La reforma constitucional: la organización territorial del Estado, la Unión Europea y la igualdad de género, Biblioteca Nueva, Madrid, 2005, pp. 281-336.

TAJADURA TEJADA, J., «Inclusión en las Comunidades Autónomas en la Constitución», ÁLVAREZ JUNCO, J., RUBIO LLORENTE, F. (eds.), El informe del Consejo de Estado sobre la reforma constitucional: texto del informe y debates académicos, CEPC y Consejo de Estado, Madrid, 2006, pp. 627-651.

TORRES-DULCE LIFANTE, E., «Comentario sobre la reforma del título VIII de la CE: del vaciamiento del título a su reconstrucción reformadora», VV. AA., La reforma constitucional, Ministerio de Justicia, Madrid, 2005, pp. 399-404.

VILALTA FERRER, M., «La reforma del sistema de financiación de las Comunidades Autónomas», GARCÍA HERRERA, M. A., VIDAL BELTRÁN, J. M., El Estado Autonómico: integración, solidaridad, diversidad, Colex, INAP, Madrid, 2005, Vol. 1, pp. 635-652.

VIVER PI-SUNYER, C., «La reforma de los Estatutos de Autonomía», VV. AA., La reforma constitucional, Ministerio de Justicia, Madrid, 2005, pp. 251-268

VIVER PI-SUNYER, C., «La reforma de los Estatutos de Autonomía», GARCÍA HERRERA, M. A., VIDAL BELTRÁN, J. M., El Estado Autonómico: integración, solidaridad, diversidad, Colex, INAP, Madrid, 2005, Vol. 2, pp. 233-250.

\section{INTEGRACIÓN EUROPEA Y REFORMA CONSTITUCIONAL}

ALBERTÍ ROVIRA, E., «La cláusula europea en la Reforma de la Constitución española», ÁlVAREZ JUNCO, J., RUBIO LLORENTE, F. (eds.), El informe del Consejo de 
Estado sobre la reforma constitucional: texto del informe y debates académicos, CEPC y Consejo de Estado, Madrid, 2006, pp. 457-482.

ALEGRÍA, A., «Reforma constitucional, Unión Europea y Comunidades Autónomas», ARRANZ DE ANDRÉS, C., SERNA VALLEJO, M., Estudios de Derecho español y europeo: libro conmemorativo de los primeros 25 años de la Facultad de Derecho de la Universidad de Cantabria, Universidad de Cantabria, Santander, 2009, pp. 521-540.

ALLUÉ BUIZA, A., «Dinámica de la reforma comunitaria desde la perspectiva de la reforma constitucional», VV. AA., La constitución española en el ordenamiento comunitario europeo (I): XVI Jornadas de Estudio, Ministerio de Justicia, Madrid, 1995, Vol. I, pp. 1055-1068.

ALONSO DE ANTONIO, J. A., «El derecho de sufragio de los ciudadanos europeos y la reforma de la Constitución», VV. AA., La constitución española en el ordenamiento comunitario europeo: XVI Jornadas de Estudio, Ministerio de Justicia, Madrid, 1995, Vol. I, pp. 1069-1088.

ALONSO DE ANTONIO, J. A., «El derecho de sufragio de los extranjeros en las elecciones municipales y la reforma de la constitución», VV. AA., IV Jornadas de Derecho Parlamentario: Reflexiones sobre el régimen electoral, enero 1993, Congreso de los Diputados, Madrid, 1997, pp. 917-941.

ALONSO GARCÍA, R., «Reforma constitucional: la recepción en la Constitución del proceso de construcción europea», ÁLVAREZ JUNCO, J., RUBIO LLORENTE, F. (eds.), El informe del Consejo de Estado sobre la reforma constitucional: texto del informe y debates académicos, CEPC y Consejo de Estado, Madrid, 2006, pp. 557-561.

ARAGÓN REYES, M., «La Constitución española y el Tratado de la Unión Europea: la reforma de la Constitución», Revista Española de Derecho Constitucional, núm. 42, 1994, pp. 9-26.

BAR CENDÓN, A., «El Tratado de Lisboa y la reforma constitucional de la Unión Europea», Cuadernos constitucionales de la Cátedra Fadrique Furió Ceriol, núm. 60-61, 2007, pp. 183-220.

CARDONA LLORENS, J., «Declaración del Tribunal Constitucional de 1 de julio de 1992 sobre el Tratado de la Unión Europea», Noticias de la Unión Europea, núm. 10, 1994, pp. 27-36.

ESCOBAR HERNÁNDEZ. C., «La cláusula europea en la Constitución española: (algunas reflexiones para una eventual reforma constitucional)», ÁLVAREZ JUNCO, J., RUBIO LLORENTE, F. (eds.), El informe del Consejo de Estado sobre la reforma constitucional: texto del informe y debates académicos, CEPC y Consejo de Estado, Madrid, 2006, pp. 483-499.

GARCÍA GESTOSO, N., «Algunas consideraciones sobre la reforma de la Constitución española de 1978 derivadas de la integración europea», Parlamento y Constitución, núm. 8, 2004, pp. 101-138.

GARCÍA GESTOSO, N., «El proceso de integración europea y la Constitución Española de 1978: reflexiones sobre la necesidad o conveniencia de reformar nuestra Constitución para adaptarla a la dinámica europea», ROURA GÓMEZ, S. A., TAJADURA 
TEJADA, J. (coords.), La reforma constitucional: la organización territorial del Estado, la Unión Europea y la igualdad de género, Biblioteca Nueva, Madrid, 2005, pp. 401-478.

GARCÍA-DOBARCO GONZÁLEZ, B., «Reforma constitucional y Unión Europea: notas para un debate político», Revista española de la función consultiva, núm. 4, (Ejemplar dedicado a: Reforma de los Estatutos de Autonomía y Reforma de la Constitución), 2005, pp. 91-104.

HERRERO y RODRÍGUEZ DE MIÑÓN, M., «Europeización de la Constitución española (contribución a la reforma constitucional)», Anales de la Real Academia de Ciencias Morales y Políticas, núm. 83, 2006, pp. 385-414.

JIMENA QUESADA, L., «La actualización de la Constitución Española ante la Carta de derechos fundamentales de la Unión Europea», ROURA GÓMEZ, S. A., TAJADURA TEJADA, J. (coords.), La reforma constitucional: la organización territorial del Estado, la Unión Europea y la igualdad de género, Biblioteca Nueva, Madrid, 2005, pp. 479-522.

LÓPEZ AGUILAR, J. F., «La reforma de la Constitución: opciones constitucionales ante la ratificación de los Acuerdos de Maastricht», Revista de Derecho Político, núm. 36 (especial sobre La reforma constitucional), 1992, pp. 439-457.

LÓPEZ AGUILAR, J., «Maastricht y la problemática de la reforma de la Constitución», Revista de Estudios Políticos, núm. 77, 1992, pp. 57-93.

LÓPEZ CASTILLO, A., «A propósito de la proyectada articulación de una cláusula europea en la CE: (propuesta y apuntes para el debate)», ÁLVAREZ JUNCO, J., RUBIO LLORENTE, F. (eds.), El informe del Consejo de Estado sobre la reforma constitucional: texto del informe y debates académicos, CEPC y Consejo de Estado, Madrid, 2006, pp. 501532.

MANGAS MARTÍN, A., «La Declaración del Tribunal Constitucional sobre el artículo 13.2 de la Constitución: una reforma constitucional innecesaria», Revista Española de Derecho Internacional, núm. 44, 1992, pp. 381-393.

MANGAS MARTÍN, A., «Los Tratados internacionales (Artículos 93 a 96 de la CE): especial referencia a la ciudadanía europea», Revista de Derecho Político, núm. 36 (especial sobre La reforma constitucional), 1992, pp. 419-438.

MANGAS MARTÍN, A., «La reforma del Art. 93 de la Constitución española», ÁlVAREZ JUNCO, J., RUBIO LLORENTE, F. (eds.), El informe del Consejo de Estado sobre la reforma constitucional: texto del informe y debates académicos, CEPC y Consejo de Estado, Madrid, 2006, pp. 533-556.

MARTÍNEZ VAL, J. M., «La Declaración del Tribunal Constitucional de 1 de julio de 1992 sobre la reforma del artículo 13.2 de la Constitución», Revista General de Derecho, núm. 576, 1992, pp. 8149-8154.

PÉREZ TREMPS, P., «El alcance jurídico y político de la primera reforma constitucional en España», VV. AA., V Congreso Iberoamericano de derecho constitucional, UNAM, México, 1998, pp. 735-749.

PÉREZ VERA, E., «De los españoles y extranjeros», Revista de Derecho Político, núm. 36 (especial sobre La reforma constitucional), 1992, pp. 73-98. 
PRADA FERNÁNDEZ DE SANMANED, J., «Examen de urgencia de la alternativa entre reforma y mutación constitucional ante la integración europea», VV. AA., Estudios de derecho público. Homenaje a Juan José Ruiz-Rico, Tecnos, Madrid, 1997, pp. 299332.

RALLO LOMBARTE, A., «El Tratado de Maastricht y el Derecho de Sufragio de los extranjeros en España», Revista de Derecho Político, núm. 36 (especial sobre La reforma constitucional), 1992, pp. 89-128.

RODRÍGUEZ, A., «Ciudadanía europea, derechos sociales y Estatutos de Autonomía: tres propuestas de reforma», GARCÍA HERRERA, M. A., VIDAL BELTRÁN, J. M., El Estado Autonómico: integración, solidaridad, diversidad, Colex, INAP, Madrid, 2005, Vol. 1, pp. 517-526.

SIEIRA MUCIENTES, S., «Reforma constitucional en materia de objeción de conciencia: una aproximación de la Constitución Española a la Carta de Derechos Fundamentales de la Unión Europea», Parlamento y Constitución, núm. 8, 2004, pp. 169-184.

SOLOZÁBAL ECHEVARRÍA, J., «El Tratado Constitucional europeo y la reforma de la Constitución española», Revista del Ministerio de Trabajo e Inmigración, núm. 57, 2005, pp. 33-48.

\section{LA REFORMA DEL ARTÍCULO 135}

ALVÁREZ CONDE E., SOUTO GALVÁN, C., La constitucionalización de la estabilidad presupuestaria, Universidad Rey Juan Carlos, Madrid 2012.

BLANCO VALDÉS, R. L., «La reforma de 2011: de las musas al teatro, Claves de Razón Práctica, núm. 216, 2011, pp. 8-18.

DOMÍNGUEZ MARTÍNEZ, J. M., LÓPEZ JIMÉNEZ, J. Mª , «Estabilidad presupuestaria y reforma constitucional en España», Diario La Ley, núm. 7760 (Jueves, 22 de diciembre) 2011, pp. 1-8.

FALCÓN Y TELLA, R. «La reforma del Art. 135 de la Constitución», Revista General de Derecho Europeo, núm. 25, 2011.

GORDILLO PÉREZ, L. I., «A propósito de la reforma constitucional de 2011», El Cronista del Estado Social y Democrático de Derecho, núm. 25, 2012, pp. 32-37.

MARTÍNEZ LAGO, M. A., «Crisis fiscal, estabilidad presupuestaria y reforma de la Constitución», El Cronista del Estado Social y Democrático de Derecho, núm. 24, 2011, pp. $10-21$.

PALMA FERNÁNDEZ, J. L., "Claves de la reforma del artículo 135: Derecho constitucional para financieros (sobre joyas, collares y relojes)», Diario La Ley, núm. 7713 (11 de octubre) 2011.

TAJADURA TEJADA, J., «Reforma constitucional e integración europea», Claves de Razón Práctica, núm. 216, 2011, pp. 20-29 
VV.AA., «La reforma del artículo 135 CE», Revista Española de Derecho Constitucional, núm. 93, 2011, pp. 159-210.

$$
* * *
$$

TITLE: Bibliographic Repertory on the Constitutional Reform.

ABSTRACT: The present repertoire gathers the various doctrinal contributions (books, chapters, critical studies...) which have analyzed the Constitutional Reform from different legal perspectives. In order to facilitate the use of the repertoire, the studies are classified in different sections according with its topic. Basically, all the contributions may be included under the general theory of the Constitutional reform, the Crown, the Senate, Autonomous Communities and Europe.

RESUMEN: El presente repertorio bibliográfico recoge los diversos estudios, ya sean monografías artículos en revistas especializadas o capítulos de libros, que han abordado desde distintas perspectivas la reforma constitucional y sus implicaciones. Para facilitar el manejo del repertorio, los distintos estudios se encuadran, según sea su temática principal, en alguno de los apartados en los que se divide. Básicamente, todos ellos son reconducibles a la teoría general de la reforma, la Corona, el Senado, las Comunidades Autónomas y Europa.

KEY WORDS: Constitutional Reform. Repertoire.

PALABRAS ClaVE: Reforma constitucional. Repertorio.

FECHA DE RECEPCIÓN: 17.01.2012 FECHA DE ACEPTACIÓN: 15.02.2012 